\title{
Onsite Testing of Ammonium Oxalate Treatment Applied to Historical Salt-Infested Limestone
}

\author{
Tabitha Dreyfuss and JoAnn Cassar \\ Department of Conservation and Built Heritage, Faculty for the Built Environment, University of Malta, Msida, MSD 2080, Malta
}

\begin{abstract}
Ammonium oxalate treatment, previously extensively studied on limestone in the laboratory, was applied to powdering historical stonework (limestone) situated on the shoreline in the Mediterranean Island of Malta. This paper presents the results obtained from onsite testing that aimed at evaluating the treatment in terms of its aesthetic performance, the depth of treatment, the mechanical properties of the consolidated stone and the influence on water transport. To this end, the testing program included colorimetry, DRMS (drilling resistance measurement system) and water absorption through the contact sponge method. This study is Part One of the final phase of a wider research program which included two previous phases progressing from treating this same very porous stone type in a laboratory-based controlled environment to uncontrolled site conditions, seeking to quantify this treatment's effectiveness in the field. Results showed that onsite consolidation was achieved and that although some changes in colour and water absorption were brought about by the treatment, these were within acceptable tolerance limits. Besides carrying out these treatments and evaluations directly on the coast, this study anticipates further studies which will look at rural and urban sites where the types and concentrations of salts are expected to be different.
\end{abstract}

Key words: Historical stonework, limestone consolidation, ammonium oxalate treatment, onsite treatment, onsite testing.

\section{Introduction}

The Maltese Islands in the central Mediterranean, measuring $316 \mathrm{~km}^{2}$ and located $93 \mathrm{~km}$ south of Sicily and $288 \mathrm{~km}$ north of Africa are home to an immense wealth of architectural heritage which dates back to prehistoric times. These buildings and monuments were built using Maltese Globigerina Limestone-a highly porous calcareous stone (up to $41 \%$ porosity). This stone occurs as a range of types where the two extreme ends include the more durable franka which usually weathers well and the less durable soll which deteriorates badly even in the same environment. Previous research [1] found the porosity accessible to water to be greater in franka (21.36\%) than in soll (19.48\%). The percentage of mesopores $(6 \mathrm{~nm}<\varnothing<$ $50 \mathrm{~nm}$ ) was $12.60 \%$ in franka and $24.35 \%$ in soll while the percentage of macropores $(\varnothing>50 \mathrm{~nm})$ was found

Corresponding author: Tabitha Dreyfuss, Dr, postdoctoral researcher, research fields: architectural heritage, salt-contaminated weathered limestone, limestone consolidation, in situ treatment and testing. E-mail: tdrey01@um.edu.mt. to be $87.25 \%$ in franka and $75.65 \%$ in soll [1]. The marginally higher incidence of clay minerals in soll could contribute to faster deterioration in this stone type, when compared with franka, by occluding pore space [2]. Both types visibly deteriorate in an environment that is exposed to both water and soluble salts as well as fluctuating environmental conditions, thus regularly requiring conservation action.

When the stone is not sufficiently deteriorated to warrant replacement, consolidation may be considered. This is often the case when the damaged stone is not posing a structural problem or is decorative. Unfortunately, a well-established intervention procedure does not yet exist for cases where very high salt loading is present. Globigerina Limestone which has lost cohesion, usually manifested as powdering/granular disintegration, often eventually leading to back-weathering, requires a treatment which will bridge the loose powder/grains together and bind them to the sound stone beneath while retaining the water transport properties of the stone. Ammonium oxalate 
treatment on calcareous stone has to date given promising results, suggesting its potential use in this respect.

Ammonium oxalate treatment is based on a chemical reaction between ammonium oxalate and calcium carbonate of the stone being treated, to form calcium oxalate. Naturally occurring calcium oxalate layers on stone surfaces and the protection that they provide started to be explored in Italy at the Opificio delle Pietre Dure in Florence in 1985 [3]. These naturally occurring calcium oxalate films were found to be more resistant than calcium carbonate to acid attack, and this led to studies involving the artificial formation of oxalates through ammonium oxalate treatment [4].

Studies have been carried out in recent years on the surface conversion of Maltese Globigerina Limestone to calcium oxalate $[5,6]$. These were followed by a research project where the treatment was investigated with single salts present in the stone, under laboratory, controlled conditions [7-9]. The study was later extended from the laboratory to the field, where salt-laden laboratory samples were treated and exposed on site prior to testing $[1,10]$. In general, it was concluded that, as part of the overall conservation process, ammonium oxalate treatment on weathered Globigerina Limestone containing soluble salts (chlorides, sulfates or nitrates) is very valid, but it was also decided that further in situ investigations on stone with salt mixtures and uncontrolled environmental conditions were needed.

These positive results thus initiated a large-scale research project to validate this treatment's use in actual environments and real site conditions on historical architecture built in Globigerina Limestone, where both soluble salts and water are naturally present in a fluctuating environment.

This current research includes three distinct sites - coastal, rural and urban-representing three typical site scenarios with respect to the soluble salts expected to be present. This paper discusses the results from onsite testing from the first site, St. Sebastian Bastion, Marsamxett Harbour, Valletta (Figs. 1 and 2). This is coastal bastion wall with high levels of sodium chloride.

\section{Methodology}

The study on site commenced with characterizing the stone blocks through colorimetry using a Konica Minolta spectrophotometer CM-700d, with the standard illuminant D65, observer $10^{\circ}$, target $\varnothing=$ $8 \mathrm{~mm}$ (EN 15886.2010) [11], and for hardness by DRMS (drilling resistance measurement system) $5 \mathrm{~mm}$ diamond-end drill bit at a penetration rate of $20 \mathrm{~mm} / \mathrm{min}$ and $300 \mathrm{revs} / \mathrm{s}$.

Fig. 1 Ortho map showing area studied and its proximity to the sea

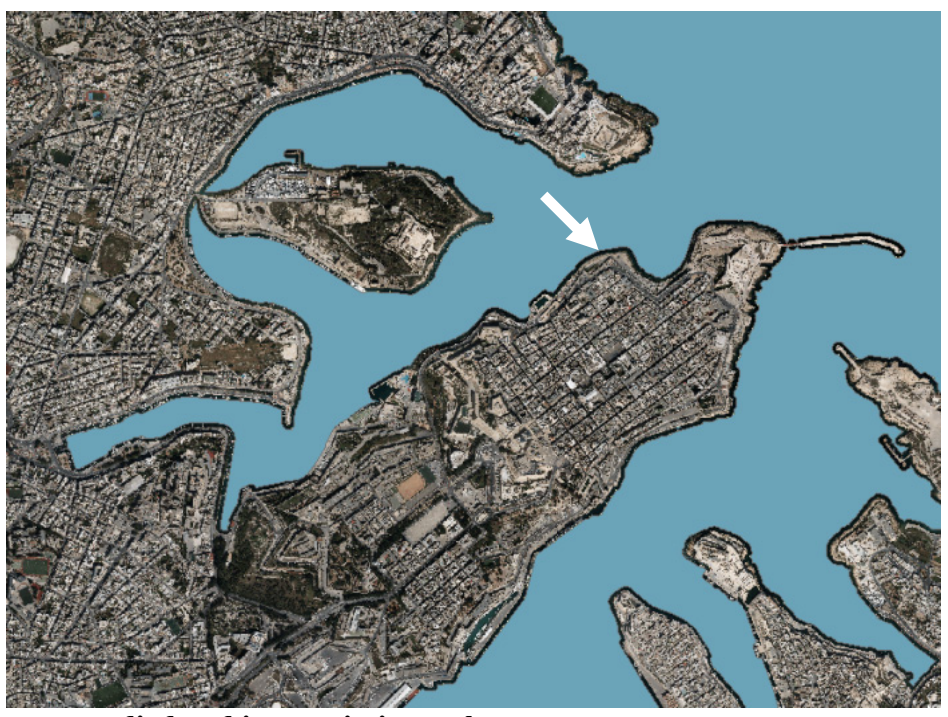

Source: Malta Environment and Planning Authority, Orthos 2016, http://geoserver.pa.org.mt/publicgeoserver. 


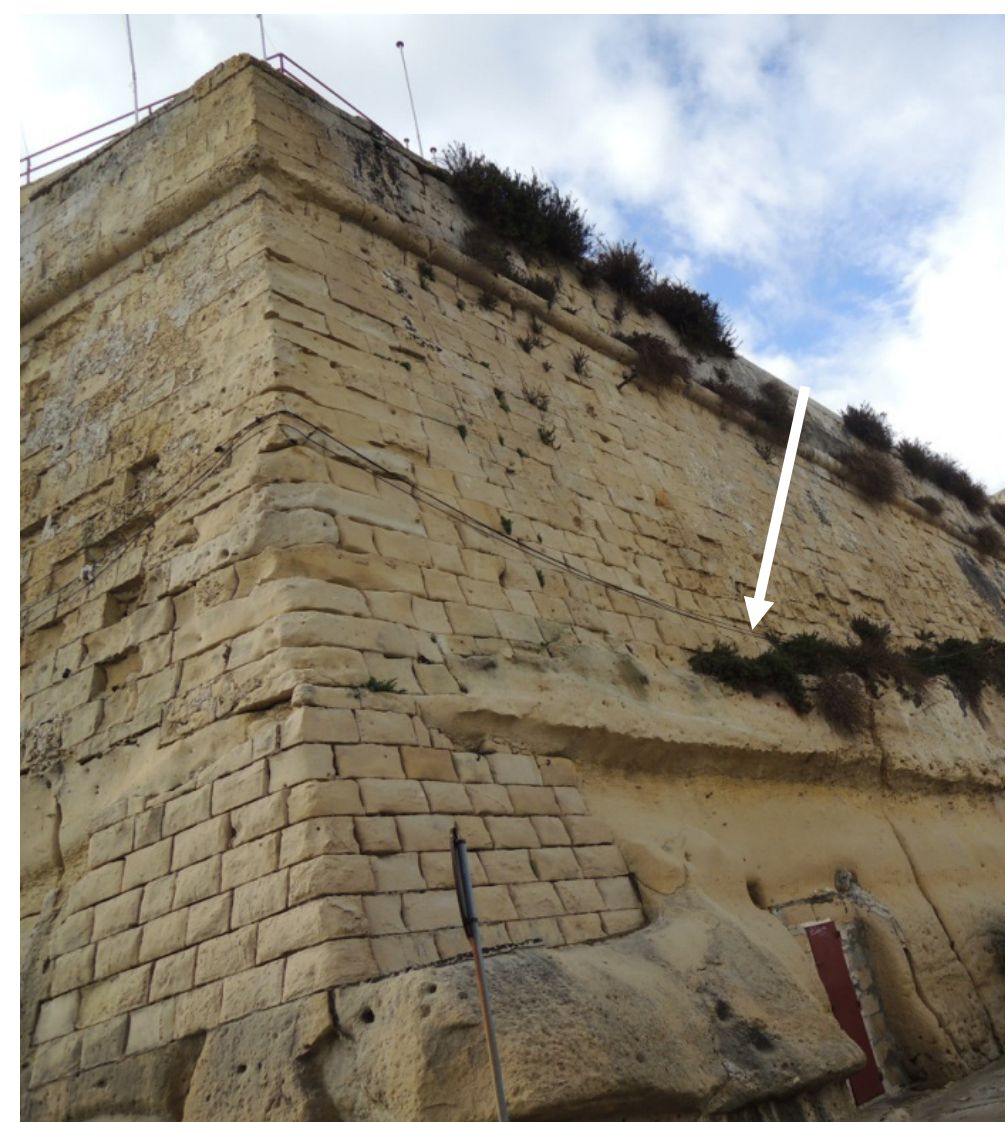

Fig. 2 St. Sebastian Bastion, Marsamxett Harbour (arrow indicates the area studied).

Two poultice types were then applied to the selected stones, one as a blank (water only) poultice and the other with ammonium oxalate. The blank poultice was used to be able to identify any effects of poulticing on the stone with water only, independently of the ammonium oxalate.

Both poultices included a cellulose pulp $(300 \mu \mathrm{m})$. The blank poultice consisted of deionised water and the treatment poultice included a $5 \%$ ammonium oxalate monohydrate solution. Both poultices were applied in situ at approximately $7 \mathrm{~m}$ above street level (Fig. 2). The area included in the testing is illustrated in Fig. 3. The mean ambient temperature during application was $26{ }^{\circ} \mathrm{C}$ and the mean relative humidity was $72 \%$. The two poultices were applied for 24 hours and left uncovered. Following application, the still-damp poultices were manually removed and the excess pulp was brushed off with a dry, soft nylon brush. In both cases, the stone was left to air dry for 3 days at ambient conditions $\left(22-40{ }^{\circ} \mathrm{C}\right.$ temperature and
$34-89 \%$ relative humidity).

Onsite testing was then carried out, and included colorimetry, DRMS - both methods as described above for characterization - and water absorption through the contact sponge (NORMA UNI 11432:2011) [12]. All testing included 3 runs.

\section{Results and Discussions}

\subsection{Characterization}

Visual inspections were carried out at close range on the scaffolding on site. Natural differences in the stones in terms of colour, texture and deterioration pathology were observed. These differences under close-range inspection are to be expected on a historical wall that has been exposed for centuries. Within this context, those stones which were visually perceived to be most similar and having the same deterioration pathology —in this case powdering — were identified and tested for colour differences using colorimetry and 


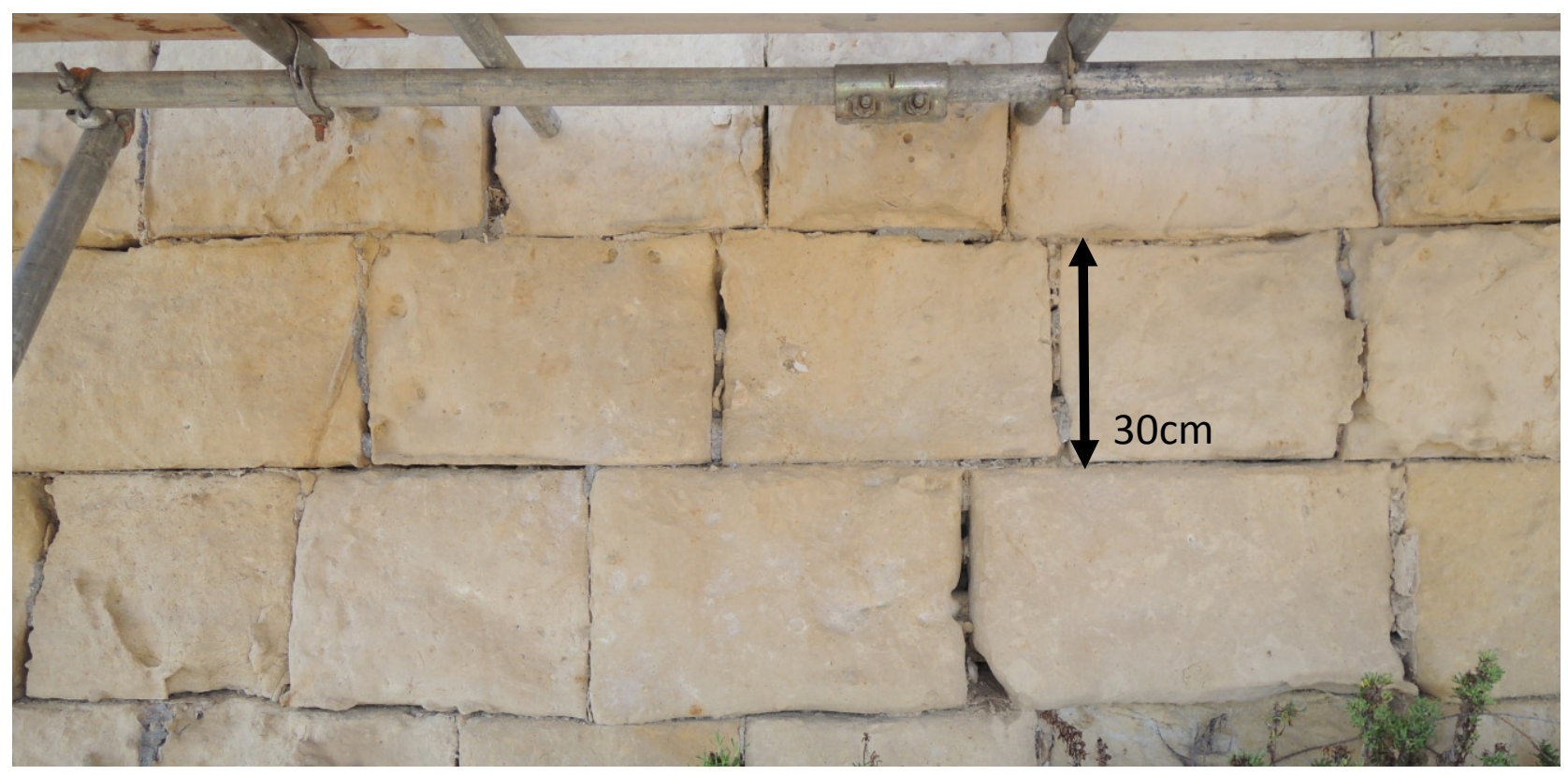

Fig. 3 Area tested; arrow in Fig. 1.

Table 1 Pre-poultice colour characterization.

\begin{tabular}{|c|c|}
\hline \multicolumn{2}{|c|}{ CHARACTERIZATION COLORIMETRY } \\
\hline \multicolumn{2}{|c|}{$\Delta \mathrm{E}$} \\
\hline COLOUR DIFFERENCE \\
BETWEEN 2 STONES \\
TO BE TESTED & $1.54 \pm 1.10$ \\
\hline
\end{tabular}

for drilling resistance using DRMS.

The $\Delta \mathrm{E}$ value before poultice application (blank and ammonium oxalate treatment) between the two stones considered in this study was $1.54 \pm 1.10$ (Table 1). A colour difference between the stones was expected and the value obtained is considered to be low (less than 5) and acceptable $[13,14]$ for direct comparison purposes with post-poultice application.

The DRMS graphs obtained for the two selected stones, which were both untreated, are illustrated in Fig. 4. The shape and ranges of these graphs were seen to be similar with an average drilling resistance of $4.43 \mathrm{~N}$ (before blank poultice) and $4.97 \mathrm{~N}$ (before treatment poultice). These are directly comparable with previously obtained results [1] where quarry Globigerina Limestone had an average drilling resistance of $4.94 \mathrm{~N}$ in the case of franka type and $7.71 \mathrm{~N}$ in the case of soll. This may suggest that the
Globigerina Limestone present on site and considered in this study is of the franka type.

In both cases (Fig. 4), the drilling resistance was less in the outermost $1.0-2.0 \mathrm{~mm}$, beyond which this datum was seen to stabilize. This implies that the weathering/powdering of the stone is located within the outer 1.0-2.0 $\mathrm{mm}$ of the stone.

\subsection{Poultice Application}

After poultice application, the colour changes recorded were $2.77 \pm 1.54$ for the blank poultice and $3.14 \pm 0.58$ for the treatment poultice (Table 2). These $\Delta \mathrm{E}$ values are greater than the colour differences between the untreated stones in the characterization phase (Table 1).

This increase is attributed, at least in part, to salt mobilization induced by the poultice action that was also observed by SEM (scanning electron microscopy) [15] and also observed by others [16].

A colour change induced through sodium chloride contamination only on franka stone in the laboratory was recorded at $2.09 \pm 0.27$ in previous research [1].

Furthermore, although the poultice was manually removed and dusted off after application, smaller particles of paper pulp inevitably get lodged within the 


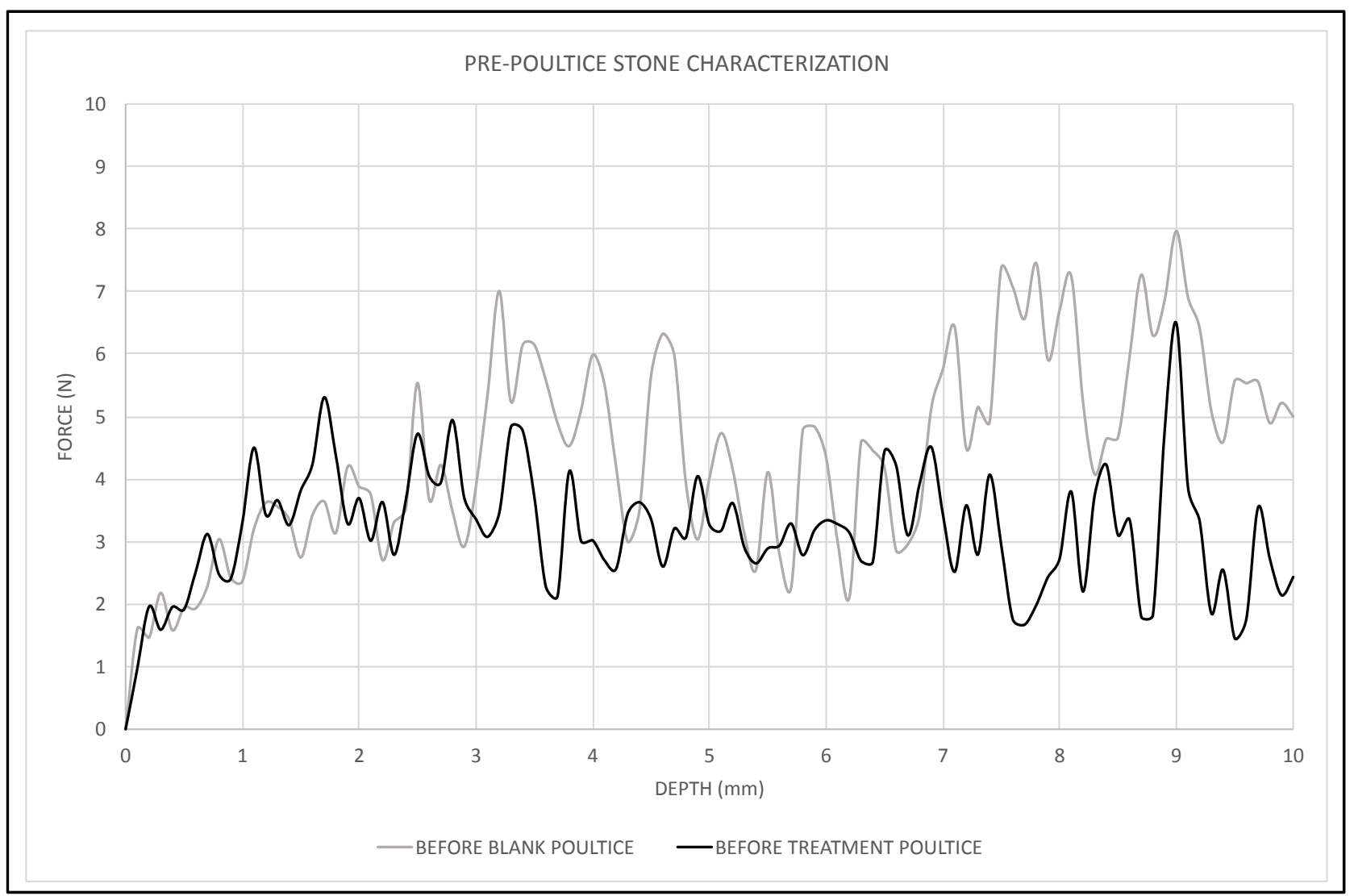

Fig. 4 DRMS stone characterization prior to poultice applications.

Table 2 Post-poultice colour change.

\begin{tabular}{|l|c|}
\hline \multicolumn{2}{|c|}{ POULTICE COLORIMETRY } \\
\hline \multicolumn{2}{|c|}{} \\
\hline BLANK POULTICE & $\mathbf{E}$ \\
\hline TREATMENT POULTICE & $2.77 \pm 1.54$ \\
\hline
\end{tabular}

surface of the weathered stone, which is not flat and smooth but rough and granular. This contributes to an additional whitening of the stone that is reflected in the $\Delta \mathrm{E}$ values.

In all cases, the $\Delta \mathrm{E}$ values obtained after poultice treatment-both blank and treatment-were within tolerance limits $(\Delta \mathrm{E}<5)[13,14]$.

After the blank poultice application, DRMS results showed an increase of $1.10 \mathrm{~N}$ within the external $1.1 \mathrm{~mm}$ of the stone's surface (Fig. 5).

This, once again, may be attributed to the mobilization of salts to the surface of the stone due to the action of the poultice, as observed in previous results [15] and by others [16] and described above.

The influence of soluble salts on the drilling resistance was also studied in previous research work $[1,17]$ where an increase was recorded from $4.94 \mathrm{~N}$ to $5.53 \mathrm{~N}$ in franka stone after contamination with sodium chloride.

This corroborates the theory that the blank poultice increased the drilling resistance of the stone post poultice application because of the salts that were brought to the surface with the poultice.

Additionally, the dissolution of calcite from within the stone and its deposition at the surface [2] is another contributing factor to this increased hardness.

After ammonium oxalate treatment, the drilling resistance registered a peak drilling resistance of $7.75 \mathrm{~N}$ within a depth of $0.6 \mathrm{~mm}$ and a general increase within the surface $1.1 \mathrm{~mm}$ when compared to the untreated stone (Fig. 6).

This increase is greater than the increase produced 


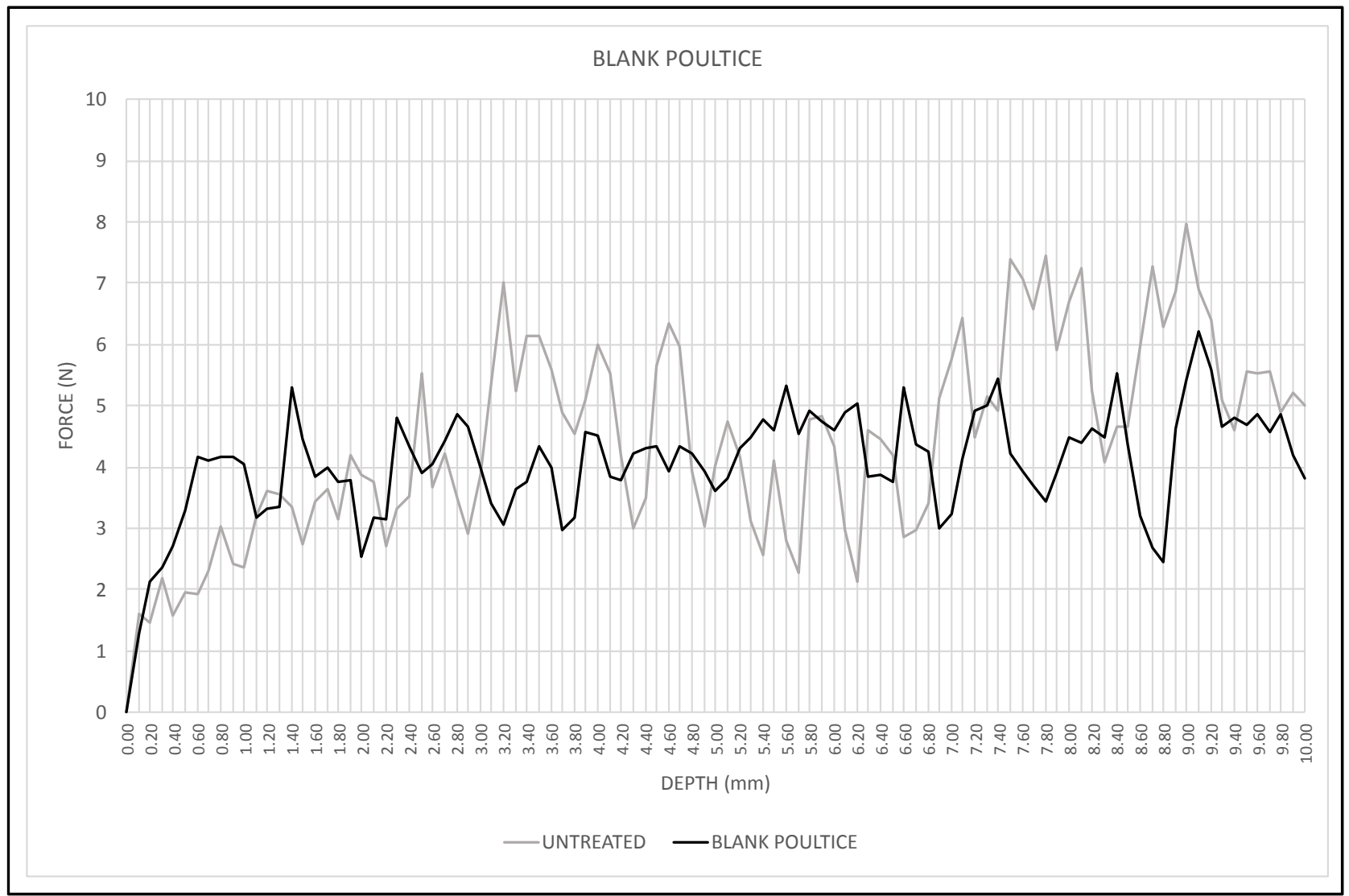

Fig. 5 DRMS before and after blank poultice application.

by the blank poultice, suggesting that besides the contribution of the mobilized salts/calcite to the drilling resistance, the ammonium oxalate also reacted with the calcium carbonate of the stone to form calcium oxalate, which is harder than calcium carbonate, therefore contributing to the increased drilling resistance.

This is in keeping with previous results obtained in the laboratory, where ammonium oxalate treatment applied to sodium chloride contaminated franka increased the drilling resistance to a maximum of $14.79 \mathrm{~N}$ which occurred up to a depth of $0.3 \mathrm{~mm}$ $[1,17]$.

In the quarry samples, during previous research $[1,17]$, the stone was intact (un-weathered) and the salt contamination was carried out using a saturated single salt solution. In this current research, the stones considered were weathered and the salt contamination was naturally occurring and contained salt mixtures.
The greater maximum drilling resistance of $14.79 \mathrm{~N}$ obtained for quarry stone when compared to the $7.75 \mathrm{~N}$ in the weathered stone may be due to actual stone pathology as well as to the amount of salts present in the stone.

Although further research is required, the reason for this difference may be due to the powdering pathology in the weathered stone, where the network of pores was disrupted through weathering, thus allowing deeper absorption of the ammonium oxalate solution and promoting the reaction further into the stone (in this case $0.6 \mathrm{~mm}$ ). In the quarry samples, the intact nature of the pore network in the stone provided more material at the surface available to react with the ammonium oxalate, which was used up before being able to penetrate further (at $0.3 \mathrm{~mm}$ ) $[1,17]$.

Therefore, although the overall amount of calcium oxalate formed is thought to be the same in both cases, since the same amount of product was applied per unit 


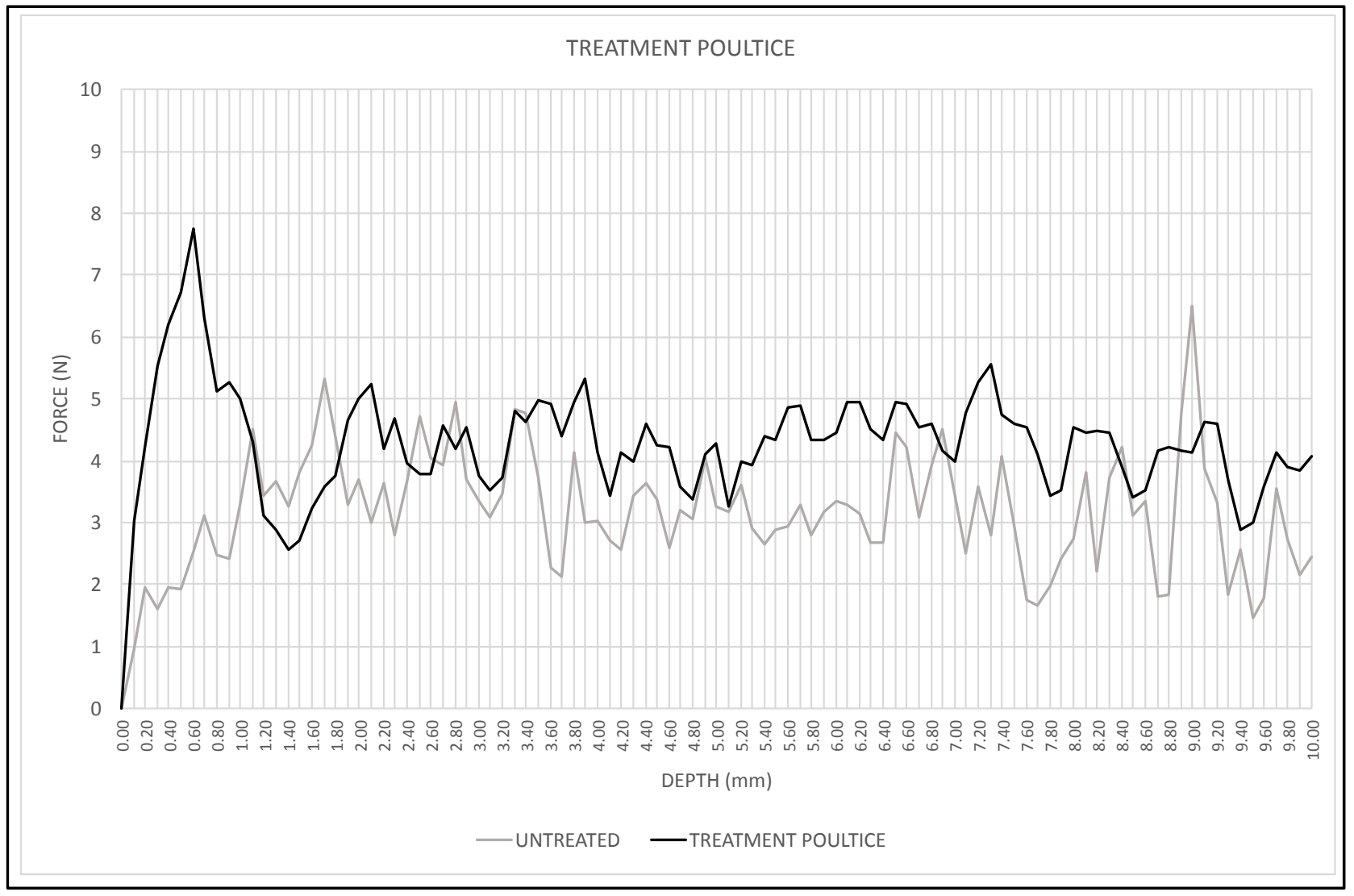

Fig. 6 DRMS before and after treatment poultice application.

Table 3 Water absorption before and after treatment.

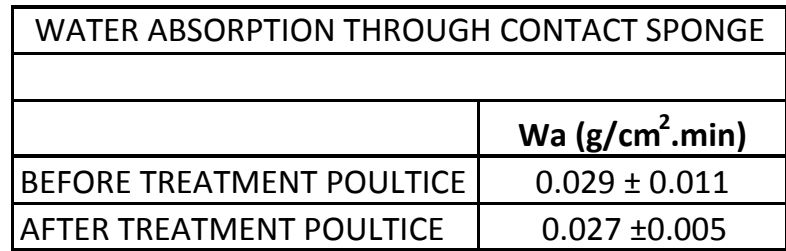

area, results indicate that calcium oxalate distribution is different and is directly related to the stone's pathology. Further research is required.

Furthermore, the incidence of soluble salts on the stone's surface, which was greater in the quarry samples [1, 17], when compared to the site samples, may also contribute to the shallower depths recorded in the former case, through the blocking of pores.

Water absorption through the contact sponge test showed a slight reduction from $0.029 \pm 0.011$ $\mathrm{g} / \mathrm{cm}^{2} \cdot \min$ to $0.027 \pm 0.005 \mathrm{~g} / \mathrm{cm}^{2} \cdot \min$ following ammonium oxalate treatment (Table 3 ).

This reduction is considered to be low and acceptable, and indicates that water transport in the liquid phase by capillarity, after ammonium oxalate treatment, is still possible in the stone.

\section{Conclusions}

Some important conclusions may be drawn from this study, which are specific to onsite testing. From a diagnostic point of view, the tests used to characterize the stone - colorimetry and DRMS - show that relevant information can be obtained by non-destructive and micro-destructive tests, which may serve to characterize the stone as well as to establish baseline data prior to intervention.

This study also highlights that some of the changes to treated stone, may be due, at least in part, to the application method as well as to the treatment itself, as was proved by the blank poultice where changes in colour and drilling resistance were recorded even though no ammonium oxalate was used. Although 
colour changes were also recorded with ammonium oxalate treatment, these were all within acceptable tolerance limits.

The stone's pathology - intact versus weathered - as well as the concentration of soluble salts present in the stone before treatment, were both seen to influence the distribution of the calcium oxalate within the treated stone, although the overall amount of ammonium oxalate applied was the same.

The retained water transport properties in the liquid phase after treatment show that ammonium oxalate treatment on Globigerina Limestone in situ in the presence of naturally occurring sodium chloride (and possibly other salts) does not hinder the continued permeability of the stone.

Finally, the range of tests considered which covers the overarching properties of aesthetics, depth of treatment, physical characteristics and water transport, may be considered to be pertinent to the general case where a historical building is to undergo restoration/conservation interventions, for both general characterization as well as post-intervention evaluation.

\section{Further Research}

Ongoing research includes further testing of the same site samples discussed in this paper. These include XRD (X-ray diffraction) and ion chromatography to evaluate the mineralogical and chemical composition of untreated and treated stone. Additionally, helium pycnometry and mercury intrusion porosimetry are also envisaged and aimed at determining the porosity and pores size distributions of the untreated and treated stones.

Preparations for two other sites representative of a rural and urban environment are underway. Research is ongoing.

\section{Acknowledgments}

This research work is being funded by the REACH HIGH Scholars Program-Post-Doctoral Grants. The grant is part-financed by the European Union,
Operational Program II-Cohesion Policy 2014-2020 investing in human capital to create more opportunities and promote the wellbeing of society (European Social Fund).

The site at St. Sebastian Bastion, Marsamxett Harbour, Valletta, Malta, was made available for testing by the Restoration Directorate of the Government of Malta.

\section{References}

[1] Dreyfuss, T. 2014. "Ammonium Oxalate Treatment for the Conservation of Weathered Globigerina Limestone." A thesis submitted to the University of Malta for the degree of Doctor of Philosophy in the Department of Built Heritage, Faculty for the Built Environment, University of Malta.

[2] Cassar, J. 2002. "Deterioration of the Globigerina Limestone of the Maltese Islands." In Natural Stone, Weathering Phenomena, Conservation Strategies and Case Studies, edited by Siegesmund, S., Weiss, T., and Vollbrecht, A. London: Geological Society London, 33-49.

[3] Matteini, M., and Moles, A. 1986. Le Patine di Ossalato di Calico sui Manufatti in Marmo. OPD Restauro, Restauro del Marmo-Opere e Problemi (Calcium Oxalate Patinas on Marble Artefacts. OPD Restauro, The Restoration of Marble-Works and Problems.). Firenze: Opus Libri. (in Italian)

[4] Matteini, M., Moles, A., and Giovannoni, S. 1994. "Calcium Oxalate as a Protective Mineral System for Wall Paintings: Methodology and Analyses." Presented at the 3rd International Symposium on the Conservation of Monuments in the Mediterranean Basin, Venice, Italy.

[5] Taniguchi, Y., Shimadzu, Y., Kakoulli, I., and Giovannoni, S. 2003. "Conservation of Globigerina Limestone Monument in Malta (II)." English abstract of poster presentation. Presented at the 25th Annual Conference of Japan Society of Conservation for Cultural Property, Kyoto Zokei University, Malta Centre for Restoration, Malta.

[6] Croveri, P. 2004. "Metodologie di Consolidamento di Materiali Lapidei Nell'Area Mediterraneo: La Globigerina Limestone Maltese-Degrado e Consolidamento (Consolidation methodologies for stone materials in the Mediterranean area: The Maltese Globigerina Limestone-Deterioration and Consolidation.)." Dottorato di Ricerca in Scienza per la Conservazione dei Beni Culturali XVII cicolo, Universita degli Studi di Firenze. (in Italian) 
[7] Mifsud, T., and Cassar, J. 2006. "The Treatment of Weathered Globigerina Limestone: The Surface Conversion of Calcium Carbonate to Calcium Oxalate." In Heritage, Weathering \& Conservation, edited by Fort, R., Alavrez de Buergo, M., Gomez-Heras, M., and Vazquez-Calvo C. London: Taylor \& Francis Group, 727-34.

[8] Dreyfuss, T., and Cassar, J. 2012. "The Performance of an Induced Calcium Oxalate Surface on Globigerina Limestone." Presented at the 12th International Congress on the Deterioration and Conservation of Stone, Columbia University, New York. Accessed February 17, 2017. http://iscs.icomos.org/pdf-files/NewYorkConf/dreycass.p df.

[9] Dreyfuss, T., and Cassar, J. 2013. "Ammonium Oxalate Treatment Application in the Presence of Soluble Salts: Laboratory Results on Soft Limestone.” In Built Heritage: Monitoring Conservation Management, edited by Toniolo, L., Boriani, M., and Guidi, G. Springer, 403-12.

[10] Dreyfuss, T., and Cassar, J. 2016. "The Natural Weathering of an Artificially Induced Calcium Oxalate Patina on Soft Limestone." In Science and Art: A Future for Stone: Proceedings of the 13th International Congress on the Deterioration and Conservation of Stone, edited by Hughes, J., and Howind, T. Volume II. Paisley: University of the West of Scotland, 737-44.

[11] EN 15886. Conservation of Cultural Property-test Methods-Colour Measurement of Surfaces. CEN, European Committee for Standardization, September 2010.

[12] NORMA UNI 11432. 2011 Beni Culturali-Materiali Lapidei Naturali ed Artificiali-Misura Della Capacita di
Assorbimento di Acqua Mediante Spugna di Contatto. (Cultural Heritage-Natural and Artificial Stone Materials-Measurement of the Water Absorption Capacity through the Contact Sponge). (in Italian)

[13] Sasse, H. R., and Snethlage, R. 1997. "Methods for the Evaluation of Treatments." In Saving Our Architectural Heritage; the Conservation of Historic Stone Structures, edited by Baer, N. S., and Snethlage, R. Dahlem workshop reports, Wiley, 223-43.

[14] Bonazza, A., Vidorni, G., Natali, I., Giosuè, C., Tittarelli, F., and Sabbioni, C. 2016. "Field Exposure Tests to Evaluate the Efficacy of Nano-structured Consolidants on Carrara Marble." In Science and Art: A Future for Stone: Proceedings of the 13th International Congress on the Deterioration and Conservation of Stone, edited by Hughes, J., and Howind, T. Volume I. Paisley: University of the West of Scotland, 281-8.

[15] Dreyfuss, T., Cassar, J., Cassar, G., and Vella, D. 2017. "Study of Calcium Oxalate Crystals Formed in Salt-Contaminated Limestone." To be presented at the 16th Euroseminar on Microscopy applied to Building Materials, 14th-17th May, 2017, Les Diablerets, Switzerland. (in Press)

[16] Godts, H., De Clercq, H., and Debailleux, L. 2016. "Salt Extraction by Poulticing Unravelled?." In Science and Art. A Future for Stone: Proceedings of the 13th International Congress on the Deterioration and Conservation of Stone, edited by Hughes, J., and Howind, T. Volume I. Paisley: University of the West of Scotland, 333-42.

[17] Dreyfuss, T., and Cassar, J. (in Preparation). "Consolidation of a Soft and Porous Limestone: From the Laboratory to the Field." 